ISSN 0001-6002/2002/44/1/10-18

A cta M édica Costarricense, $\bigcirc 2002$

Colegio de M édicos y Cirujanos

\title{
Vertigo: una visión otorrinolaringológica para la medicina general
}

\author{
Federico Murillo-González, ${ }^{1}$ Zita Maía Víquez Pineda ${ }^{2}$
}

\begin{abstract}
Resumen: Muchos padecimientos se presentan con diversos síntomas que son descritos como "vértigo" o "mareo". Desde enfermedades inocentes hasta padecimientos potencialmente mortales pueden presentarlo, lo que genera cierta atmósfera de temor a enfrentarse con la tarea de llegar a un diagnóstico por parte del médico. Este trabajo trata de resumir la experiencia práctica del otorrinolaringólogo, dirigida a mejorar la capacidad resolutiva. Se describen las características y las causas del vértigo periférico y central, continuando con al gunas recomendaciones para su tratamiento, y termina con la propuesta de un algoritmo general de cuatro pasos.
\end{abstract}

Descriptor es: V értigo, neuronitis vestibular, vértigo postural paroxístico benigno

Recibido: 28 de setiembre, 2001

Acepatado para publicación: 22 de enero, 2002

En el lenguaje coloquial se usa con frecuencia el término "mareo", el cual es demasiado vago e impreciso para ser utilizado en el ejercicio semiológico. Por eso es necesario diferenciarlo, entre otros, entre lipotimia, náuseas, sensación de inseguridad, ataxia, dismetría, desorientación, debilidad de miembros inferiores, síncope y vértigo. A este último se le define como "alucinación de movimiento" 1,23,4. Refiriéndose a la percepción de movimiento inexistente, los pacientes sue len expresarlo como "que las cosas dan vueltas", "que ellas dan vueltas", "se hunde el piso", "caigo por un hueco", "se mueve el piso". Expresiones como "me voy para un lado", "flotar" o "irse para adelante o hacia atrás" no denotan vértigo, pero sí suelen indicar un trastorno de los mecanismos del equilibrio.

\section{Fisiología del equilibrio}

A ctividades como lanzar una pelota mientras se corre, en el que interviene todo el cuerpo, requiere de una gran coordinación de los movimientos involucrados, para lo cual

\footnotetext{
1 Servicio de Otorrinolaringología, Hospital Nacional de Niños, CCSS Servicio de Otorrinolaringología, Clínica M arcial Fallas, CCSS Profesor de la Escuela de Audiología y de la Escuela de Terapia de lenguaje de la Universidad Santa Paula

$2 \quad$ Clínica de Guararí, CCSS
}

Correspondencia: Federico M urillo González. A pdo. 640- Heredia. E-mail fedemuri@yahoo.com. Fax 2595411 se necesita disponer constantemente de información sobre la posición de las diferentes partes del organismo, además de la velocidad, aceleración y dirección de estas y su relación con el medio. Esta información es obtenida fundamentalmente de tres fuentes: el vestíbulo (oído), la visión y la propiocepción ${ }^{4,5,6}$. Estas sensaciones se integran de manera compleja en el tallo cerebral, cerebelo y cerebro, con el fin de generar respuestas adecuadas para mantener la postura y lograr un movimiento fluido y preciso ${ }^{1,4}$.

La propiocepción consiste esencialmente en la habilidad de sentir en que posición relativa y espacial están las estructuras somáticas del organismo (brazos, dedos, pies, etc.).

Los receptores del vestíbulo se alojan en la porción posterior del laberinto en el oído interno. Las ámpulas de los canales semicirculares son detectores de aceleración angular (sensibles a los cambios de dirección de la cabeza) y las máculas del sáculo y del utrículo son detectores de aceleración lineal (por ejemplo, aceleración hacia arriba 0 abajo, adelante y atrás) ${ }^{4,6}$. Es importante notar que este órgano prácticamente no interviene en el equilibrio cuando el cuerpo no está en movimiento.

La visión es un telesentido, permite recoger información de los objetos y el medio circundante. Su función se encuentra íntimamente integrada a los demás elementos del equilibrio, a los nervios que controlan los músculos oculares (pares III, IV y VI) y del cuello, permitiendo por ejemplo, seguir objetos con la vista aún con movimientos simultáneos de la cabeza. Esta relación se pone de manifiesto con la presencia 
del nistagmo patológico en muchos padecimientos vertiginosos. La figura 1 muestra con esquema de los elementos que intervienen en el equilibrio ${ }^{45,6}$.

\section{Vértigo vestibular}

Este término se refiere a las manifestaciones clínicas que se presentan cuando ocurre un disturbio en el sistema vestibular 3 que está conformado por el laberinto posterior (vestíbulo), el octavo par craneal y los núcleos vestibulares del tallo cerebral. El "vértigo periférico" se puede considerar casi como sinónimo, pero sobrentendiendo que no se sospecha una lesión del tallo cerebral. Dado que es necesaria la perfecta coordinación entre los dos vestíbulos, es suficiente una alteración unilateral para que se presente el vértigo ${ }^{4,6}$. Las enfermedades que afectan este sistema suelen iniciar de manera aguda. Es típico que se manifiesten con una sensación intensa de girar ${ }^{7}$, que se exacerba con los movimientos de la cabeza, que disminuye considerablemente al evitarlos. Puede acompañarse de náuseas intensas y vómitos. Distinguir entre sensación de rotación del cuerpo (objetivo) o del medio circundante (subjetivo) generalmente es irrelevante ${ }^{6}$. Al hacer pruebas de provocación, se observará que el vértigo y el nistagmo, si es observable, son precedidos de un período de varios segundos (latencia). A demás, si se repite la prueba varias veces la respuesta obtenida será progresivamente de menor intensidad y duración (fatiga). M uchas veces valorar el nistagmo sin la ayuda de equipo adecuado es difícil, pero esto no impide llegar a un diagnóstico en la mayoría de los casos. Al ocurrir un daño unilateral no progresivo de un laberinto, el sistema nervioso central puede compensar el desajuste en unas horas a semanas, por lo que el vértigo disminuye hasta desaparecer o volverse casi imperceptible? El compromiso bilateral es inusual, en este caso el pronóstico es menos optimista ${ }^{8}$. Solo lesiones de la cóclea y del nervio auditivo pueden causar una hopoacusia o tinnitus unilateral, esto porque las vías auditivas se entrecruzan a múltiples niveles en el sistema nervioso central. $L$ as enfermedades son variables, a menudo con clínica superpuesta, y ningún hallazgo aislado puede asegurar un diagnóstico. El cuadro 1 resume las principales características que hacen sospechar un trastorno del sistema vestibular ${ }^{3,5,7}$.

\section{Causas del vértigo periférico}

Varias enfermedades pueden afectar los órganos vestibulares, pero la neuronitis vestibular y el vértigo postural paroxístico benigno pueden ser responsables de más del $90 \%{ }^{9,10}$. Son las dos causas de vértigo periférico con que los médicos generales deben estar familiarizados. EI cuadro 2 resume las causas más frecuentes de vértigo vestibular ${ }^{11-17}$.

\section{Neuronitis vestibular}

Con frecuencia se le denomina erróneamente "laberíntis", sin embargo, no se debe a una inflamación del laberinto, más bien se atribuye a una inflamación idiopática del nervio vestibular (porción del octavo par craneal que inerva el

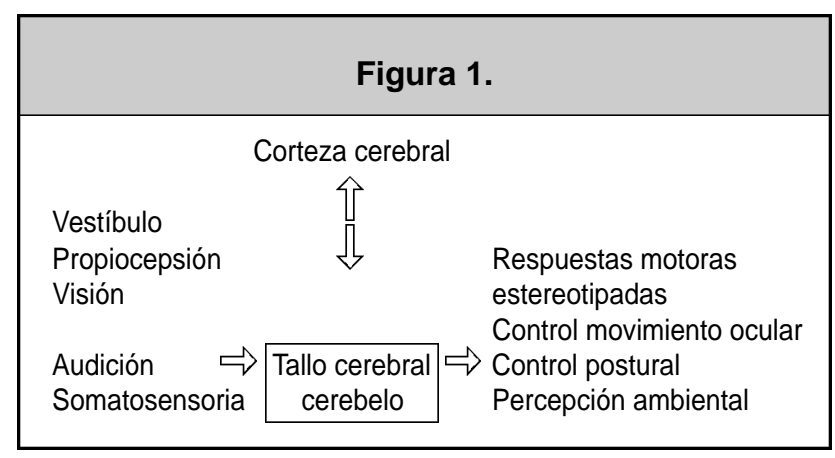

\section{Cuadro 1. Hallazgos que sugieren vértigo de origen periférico.}

- Sensación giratoria con latencia y agotable.

- Nistagmo horizontal o rotatorio con latencia y agotable.

- Se provoca al mover la cabeza.

- Desaparece en ausencia de movimiento de la cabeza.

- Desencadenada reacciones autonómicas (naúseas, vómitos, transpiración, palidez)

- Acúfeno, hipoacusia unilateral

- Parálisis facial periférica

- Ausencia de signos.

\section{Cuadro 2. Causas más frecuentes de Vértigo Vestibular.}

- Neuronitis vestibular

- Vértigo paroxístico benigno

- Cerumen impactado

- Cinetosis (mareo del viajero)

- Cuerpos extraños en conducto auditivo externo.

- Trauma del hueso temporal.

- Barotrauma

- Enfermedad de Meniere

- Ototóxicos

- Laberintitis: infecciosa, tóxica, autoinmune.

- Isquemia laberíntica aguda

- Degeneración vestibular asociada a la edad (multifactorial)

- Vestibulopatía recurrentes: cajón para los casos recurrentes inclasificables (pocos)

- Fístula perilinfática (rara)

- Tumor en hueso temporal (raro)

- Tumor del agudo pontocerebeloso (raro)

- Malformación del oído interno

- Lesión focal y exclusiva de núcleos (casi inexistente)

vestíbulo). Se han postulado teorías autoinmunes y virales para explicarlo. Su presentación es bastante homogénea, con vértigo de características vestibulares típicas, de inicio súbito, a veces la persona manifiesta que "amaneció" enfermo, otras veces se instaura progresivamente en el transcurso de unas horas ${ }^{7}$. En ocasiones hay historia de pródromos virales. Nunca hay hipoacusia o acúfeno de aparición concomitante $4,6,7$ y la otoscopia es normal. M ejora hasta la recuperación en 
el transcurso de una a tres semanas. El cuadro clínico, la ausencia de signos centrales, una audiometría simétrica o normal y unas pruebas calóricas vestibulares alteradas unilateralmente ${ }^{7,18}$ (que evidencien paresia o parálisis canal icular unilateral) establecen el diagnóstico de certeza. Las pruebas calóricas se realizan instiiando agua fría y caliente en cada oído. Por la incomodidad que pueden ocasionar y a la necesidad de experiencia para interpretarlas, esta las debe realizar el especialista y solo en casos seleccionados. La audiometría puede obviarse en ausencia de hipoacusia subjetiva si el cuadro desaparece como lo esperado en las tres primeras semanas.

\section{Vértigo postural paroxístico benigno}

Esta entidad suele presentarse después de los 40 años de edad, aunque se ha descrito hasta en niños. Se caracteriza por accesos de vértigo vestibular de unos segundos de duración predominantemente al acostarse, al levantarse 0 en posición decúbito al girar la cabeza hacia el oído afectado, por eso la persona expresa que es peor "en las noches". También puede presentarse al mirar hacia arriba 0 al agacharse. Lo fundamental es que el paciente refiere que se presenta cuando se mueve hacia una dirección específica ${ }^{17,19}$. No se presenta tinnitus ni hipoacusia. El inicio puede ser dramático, muy intenso, o discreto, poco molesto. Por lo general tiene una evolución de acrecentamiento y disminución que abarca unas tres semanas, pero algunas veces puede ser recidivante 0 crónico ${ }^{20}$. La otoscopia es normal. A veces existe el antecedente de trauma craneoencefálico, y es más frecuente en los hipertensos y diabéticos. Se le ha asociado con la presencia de pequeños cálculos en el canal semicircular posterior, que podrían ser otoconias de las máculas desprendidas por traumas o por fenómenos isquémicos, o ser consolidaciones del líquido endolinfático; de ahí los términos de cúpul olitiasis y canalolitiasis 9,10,20 con que también suele denominarse. Su diagnóstico definitivo se hace reuniendo el cuadro clínico, una audiometría simétrica 0 normal y una prueba de Dix-Hallpike positiva unilateral. Esta prueba se realiza sentando al paciente en una camilla, se le gira la cabeza $45^{\circ}$ hacia un lado, y se le acuesta rápidamente, después de un período de latencia de varios segundos el paciente manifiesta sensación de vértigo y se logra ver nistagmo cuya fase rápida se dirige hacia el suelo ${ }^{20,21}$. Esta prueba solo es de utilidad cuando se sospecha esta entidad, y los inhibidores vestibulares (ver adelante) pueden alterar los resultados.

\section{Trastorno del conducto auditivo externo}

Cuerpos extraños y cerumen, en especial si están en contacto con la membrana timpánica pueden ocasionar vértigo paroxístico de discreta intensidad ${ }^{6}$.

\section{Cinetosis}

A Igunas personas tiene una hiperreatividad constitucional del sistema vestibular. Por lo que al someterse a situaciones de estimulación intensa, como viajar en automóvil por una carretera montañosa o el movimiento de una embarcación, pueden sufrir síntomas autonómicos, en especial náuseas y vómitos, desorientación espacial y a veces vértigo manifiesto ${ }^{4,6}$. Si se someten a pruebas calóricas, la respuesta tiende a ser intensa también. Se les puede recomendar ingerir un inhibidor vestibular (ej.: dimenhidrato, difenidol, u otro antihistamínico) como profiláctico durante los viajes.

\section{Enfermedad de Meniere}

Clásicamente se describe como crisis recurrentes de vértigo vestibular e hipoacusia unilateral, de unas horas de duración 22,23, precedidos de una sensación de presión y tinnitus en el oído afecto que mejoran cuando se presenta la crisis intensa de vértigo. Pero en realidad esta entidad tiene una manera muy heterogénea de presentación ${ }^{24,25}$. Esto, unido a la poca especificidad de los hallazgos en las pruebas diagnósticas, hacen que a veces su diagnóstico sea difícil. Se le ha asociado con la presencia de hidrops endolinfático ${ }^{26}, 0$ sea, alta presión dentro del laberinto membranoso. Puede ser provocado por traumatismos craneales y sífilis, pero en la mayoría de los casos no se logra encontrar una causa, también se han propuesto teorías víricas ${ }^{27} 0$ de fenómenos autoinmunes. En el hipotiroidismo se pueden presentar cuadros similares que tienden a resolver con la restitución hormonal. Se describen diferentes tratamiento que van desde medidas dietéticas con la restricción en la ingesta de sal 7 , pasando por el uso de diuréticos, ciclos de corticoesteroides, y varios procedimientos quirúrgicos. L a elección del tratamiento depende de las particularidades del caso. Es conveniente que en su diagnóstico y manejo intervenga un otorrinolaringólogo.

\section{Laberintitis}

Las entidades en que se evidencia inflamación del oído interno son raras. El término poco definido de "laberintitis tóxica" suele referirse a los cuadros que por lo demás son compatibles con una neuronitis vestibular pero que presentan hhipoz cusia y tinnitus concomitantes ${ }^{1,18}$, aunque también podrían tratarse de un primer episodio de una enfermedad de $M$ eniere (que algunos clasifican como un tipo de laberintis crónica), o de fenómenos isquémicos laberínticos (arteriosclerosis, embolismo, compresión vascular extrínseca). La laberintitis aguda supurada, por otro lado, es una verdadera emergencia, por el peligro de sordera irreversible, o como entidad centinela de complicaciones intracraneales (abscesos, meningitis, trombosis del seno lateral), y puede presentarse en el curso de otitis medias aguas y crónicas. El vértigo es en extremo intenso, provocando postración, y siempre presenta tinnitus e hipoacusia. En la otoscopia se observan cambios inflamatorios evidentes en el oído medio u otorrea purulenta. Esta entidad amerita el internamiento en un centro que cuente con otorrinolaringólogo, la administración de altas dosis de corticoesteroides, antibióticos de amplia espectro y generalmente cirugía descompresiva ${ }^{7}$ del oído medio para extraer el tejido infectado y las secreciones purulentas, además de sellar la fístula entre los oídos medio e interno ${ }^{28}$. 


\section{Barotrauma}

Cambios bruscos en la presión ambiental que no logre equilibrar la trompa del Eustaquio con la del oído medio puede originar trastornos en el oído interno ${ }^{18,29}$, inclusive fístulas perilinfáticas. Los viajes aéreos, explosiones, manotazos sobre el pabellón auricular, zambullidas rápidas y el buceo son situaciones propicias para que esto suceda.

\section{Fístula perilinfática}

En extremo inusual, consiste en una discontinuidad de la cápsula ósea que envuelve el laberinto, estableciendo una comunicación entre el espacio perilinfático y el sistema de celdillas pneumatizadas del hueso temporal o el espacio subaracnoideo ${ }^{30,31}$. Este defecto funciona como una "tercera ventana" móvil, lo que provoca disturbios en el funcionamiento vestibular. Con frecuencia hay antecedentes de trauma cráneo-encefálico, cirugía otológica o barotrauma, pero pueden ser espontáneas. Los accesos de vértigo suelen ser muy breves (segundos) ${ }^{32}$, y se provocan con maniobras que modifican la presión en el oído medio o en el espacio subaracnoideo como las variantes del Valsalva: estornudar, toser, pujar o la maniobra de Pulitzer (espirar con la nariz y la boca cerradas). La persona también puede quejarse de vértigo cuando escucha ruidos intensos: fenómeno de Tulio ${ }^{3,33}$. A veces el ejercer presión con el dedo sobre el tragus, de tal manera que ocluya el conducto auditivo externo, hace que la presión transmitida hacia el oído medio pueda provocar vértigo: prueba de la fístula ${ }^{1,7,18}$. A demás suele acompañarse de hipoacusia neurosensorial progresiva, en este hecho radica la importancia de su diagnóstico temprano, pues solo la cirugía oportuna puede detener la pérdida de la función auditiva del oído afectado.

\section{Vértigo central}

Tiene una presentación muy heterogénea. La sensación giratoria o rotatoria pueden deberse a disturbios en la interacción entre los órganos vestibulares, el tallo cerebral y el cerebelo, por lo que no es exclusiva del vértigo vestibular. A fortunadamente la evolución y la presencia de signos neurológicos permiten hacer la diferencia. A Igunos autores consideran que el disturbio metabólico que ocasiona la hiperventilación es la causa más frecuente de vértigo central ${ }^{1,13}$. Es importante recal car que generalmente se incluyen en este apartado muchos cuadros que solo presentan sensación de desequilibrio o desorientación espacial, sin "alucinación de movimiento" como tal.

\section{Vértigo vascular}

Es frecuente que se presenten paciente quejándose de vértigo u otros malestares de breve duración (paroxismos) que se de sencadenan al levantarse 0 agacharse exclusivamente. Puede atribuirse a alteraciones en la vasorregulación cerebral. A veces puede acompañarse de visión borrosa, oscurecimiento del campo visual o lipotimia. Se presenta en todas las edades y puede deberse a infinidad de padecimientos, pero la mayoría de las veces después de un interrogatorio dirigido suele encontrarse una virosis, fatiga 0 ansiedad sostenida ("sobrecarga de trabajo"), sueño insuficiente (insomnio, apnea nocturna), fenómenos degenerativos o desnutrición (ancianos). Pero también puede presentarse en infinidad de enfermedades de compromiso sistémico: anemia, hipovolemia (incluso con hipotensión ortoestática manifiesta), insuficiencia renal, insuficiencia hepática, efectos medicamentosos (en especial con anticonvulsivantes y antihipertensivos), trastornos tiroideos, trastornos hidroelectrolíticos, hipo e hiperglucemia y otras alteraciones metabólicas ${ }^{33}$. Al desaparecer la causa subyacente o lograr controlar el vértigo desaparece.

La migraña también puede ocasionar crisis de vértigo de características variables ${ }^{33,34,35}$. Se sospecha en casos recurrentes, más si las crisis suelen durar horas. 0 tros datos sugestivos son la cefalea pulsátil (muchas veces leve), fosfenos, antecedentes familiares de migraña, crisis provocada por alimentos como el chocolate y mejoría con antimigrañosos. Es la causa más frecuente de vértigo recurrente en niños y adolescentes ${ }^{14}$.

La isquemia cerebral debida a lesión vascular directa, en especial del territorio cerebral posterior, causa con frecuencia vértigo o sensación de desequilibrio que además puede acompañarse de disartria, ataxia, oscurecimiento de la visión, disfagia u otras disfunciones de pares craneales, lipotimia, cefalea y hemiparesia ${ }^{36,37,38}$. Los cuadros de isquemia cerebral transitoria pueden acompañarse de vértigo ${ }^{33}$ a veces tan dramático que la persona no manifiesta síntomas neurológicos si no se le interroga dirigidamente al quedarse opacados por la angustia que genera la sensación vertiginosa. También debe realizarse un examen neurológico minucioso, pues los déficit pueden ser discretos ${ }^{38,39}$.

La "insuficiencia vértebro-basilar" se refiere al cuadro de vértigo u otros hallazgos neurológicos ${ }^{40,41}$ que aparecen en especial al movilizar la columna cervical, al provocarse una disminución transitoria del flujo sanguíneo en las arterias vertebrales debida a la pérdida de la flexibilidad de las mismas (arterosclerosis) y/o a la estenosis de las agujeros vertebrales cervicales ${ }^{40}$, aunque en raras ocasiones también puede deberse a compresión vascular por tumores de fosa posterior. En las radiografías simples es frecuente encontrar calcificación de las arterias vertebrales o cambios osteoartrósicos importantes.

Descensos bruscos y transitorios del gasto cardiaco pueden provocar vértigo. Datos como una enfermedad cardiaca conocida, palpitaciones previas al episodio (arritmia) ${ }^{13} 0$ de alteraciones neurológicas transitorias hacen sospechar esta etiología. La fibrilación auricular y la estenosis aórtica a veces pasan desapercibidas si no se les busca dirigidamente. Un infarto agudo del miocardio, en especial en diabéticos donde el dolor puede ser menor, puede confundirse o provocar un cuadro vertiginoso encubridor, entre otras razones porque ambos pueden presentarse con criodiaforesis, malestar epigástrico (por náuseas o vómitos en el vértigo) y sensación de malestar general. 


\section{Vértigo asociado a lesiones ocupantes de espacio}

Las neoplasias, por su naturaleza expansiva, pueden provocar mareos de aparición discreta, pero de evolución progresiva, por lo que los pacientes suelen quejarse de molestias que han tenido por semanas o meses. Casi siempre se encuentran otros signos neurológicos al realizar un examen neurológico minucioso. Es raro que el mareo produzca por sí solo un diagnóstico de tumor encefálico ${ }^{3}$. Siempre que se examine una enfermedad vertiginosa, es indispensable realizar un fondo de ojo para descartar papeledema. A veces un tumor puede ocluir agudamente un vaso intracraneano o sufrir necrosis con el consecuente edema, lo que puede provocar vértigo de características isquémicas (rápida aparición). Por esta heterogenicidad, se considera prudente realizar estudios de imágenes del contenido intracraneano en los vértigos persistentes $y$ recurrentes. El cuadro 3 resume algunas causas de vértigo central. El cuadro 4 enumera hallazgos que hacen sospechar vértigo de origen central $3,7,12,14,42,43$.

\section{Tratamiento sintomático del vértigo periférico agudo}

Los pacientes suelen sentirse mejor al acostarlos en posición de semi-Fowler. Debe asegurarse que estén hidratados, pues lo contrario aumenta el malestar. M ientras no toleren la vía oral se deben manejar en el servicio de emergencias u hospitalizados. General mente se necesita solo unas horas para estabilizarlos y tranquilizarlos para que continúen su tratamiento en el hogar. Cuando la sensación vertiginosa es muy intensa o se acompaña de náuseas y vómi tos frecuentes, es útil administrar por la vía apropiada un medicamento que inhiba la función vestibular, como los antihistamínicos o benzodiacepinas, siendo el dimenhidrato, el difenidol y el diazepan los de uso más frecuente. Estos medicamentos deben descontinuarse apenas superada la etapa aguada ya que es bien conocido que retrasan los mecanismos de compensación central, por lo que pueden prolongar el tiempo de recuperación ${ }^{44}$. No hay justificación científica para encontrar pacientes a quienes se les recetó un inhibidor vestibular para "evitar recaídas".

A unque la mayoría de los cuadros de vértigo periférico remiten espontáneamente, el estado normal y completo del equilibrio se restablece paulatinamente en el transcurso de varias semanas, durante las cuales no es conveniente que la persona se exponga a situaciones en que un episodio, aún siendo leve, podría traer graves consecuencias. Ejemplos de estas actividades son conducir un vehículo o manejar equipo pesado. El vértigo es un síntoma que a veces es difícil de objetivas, por lo que el médico puede dudar sobre la duración adecuada de la incapacidad para trabajar. Por lo general, la persona que acude con una historia coherente de vértigo periférico, rara vez es un simulador y casi siempre encaja fácilmente dentro de los cuadros más frecuentes (neuronitis vestibular y vértigo postural paroxístico benigno). La mayoría de estos casos necesitan al menos de dos semanas para recuperarse lo

\section{Cuadro 3. Causas conocidas más frecuentes de Vértigo Central}

$\begin{array}{ll}\text { Vascular } & \begin{array}{l}\text { Disturbios de la vasorregulación } \\ \text { cerebral: transtornos sitémicos } \\ \text { (toxemia infecciosa, alteraciones } \\ \text { metabólicas, medicamentoso) } \\ \text { Enfermedad cerebrovascular } \\ \text { Metabólico }\end{array} \\ \text { Tumoral } & \begin{array}{l}\text { Tronco, cerebelo o hipertensión } \\ \text { endocraneana. }\end{array} \\ \text { Degenerativo } & \begin{array}{l}\text { Esclerosis múltiple, asociada a } \\ \text { isquemia cerebral. } \\ \text { Encefalitis viral }\end{array} \\ \text { Infeccioso } & \begin{array}{l}\text { Lesión directa de tejido cerebral, } \\ \text { Epilepsia }\end{array} \\ \text { Traumático } & \text { Alcoholoma intracraneano. benzodiacepinas } \\ \text { Tóxico o medicamentoso } & \text { Estrabismo de evolución reciente. }\end{array}$

\section{Cuadro 4. Hallazgos que sugieren vértigo de origen central}

- Nistagmo vertical, cambiante, diagonal o asimétrico

- Nistagmo pendular (ambas fases de similar velocidad)

- Procedido de palpitaciones (arritmia)

- Precedido de angina

- Lipotimia

- Síncope

- Visión borrosa u oscura

- Diplopia

- Fosfenos

- Cefalea pulsátil

- Se desencadena solo al mover los ojos ( con la cabeza fija)

- Hipontensión ortoestática

- Vertigo persistente en ausencia de movimiento cefálico

- Lento progresivo por meses

- Edema de papila retineana

- Pares craneales

- Ataxia, dismetría, disartria

- Otras alteraciones neurológicas concomitantes

suficiente como para reincorporarse al trabajo con seguridad, pero no es inusuales los que necesitan hasta un mes. Cuando no se ajusten a estos parámetros es conveniente que sea valorado por un especialista. El cuadro 5 reúne una serie de indicaciones en las que debe considerarse la necesidad de realizar un estudio de imágenes (tomografía computarizada o resonancia magnética nuclear) en una crisis de vértigo agudo ${ }^{33}$.

\section{Tratamiento de la neuronitis vestibular}

Después del tratamiento sintomático inicial, es útil explicarle al paciente sobre el curso usual de la enfermedad. Después de pasar por la experiencia de una crisis de vértigo periférico 
Cuadro 5. Indicaciones para estudio de imágenes en vertigo agudo.

- Pérdida de audición asimétrica o unilateral.

- Síntomas o signos de tallo cerebral o cerebeloso

- Factores de riesgo de AVC (DM, HTA, antecedentes de IAM)

- Ataque agudo asociado a dolor cervical.

- Dirección cambiante en el nistagmo espontáneo

- Primer ataque con cefalea intensa

- Inestabilidad para permanecer de pie o caminar.

agudo las personas tienen un gran temor de que repita ${ }^{6}$. L oS tranquiliza explicarles que por lo general esto no sucede y que no es la manifestación inicial de una enfermedad más grave. A demás, suele acortar el cuadro la administración de un ciclo corto de corticoesteroires orales, por lo general prednisona a una dosis de al rededor de $0,5 \mathrm{mg} / \mathrm{kg} /$ día de 5 a 10 días ${ }^{4,6.9}$. A lgunos han propuesto el uso de antivirales, pero esto es aún objeto de controversia. Los ejercicios de provocación (hay muchas variantes), después de tranquilizar al paciente, pueden acelerar la compensación central y hacer que la crisis sea menos prolongada $7,9,45,46$.

\section{Tratamiento del vértigo postural paroxístico benigno}

Por ser una entidad que general mente remite espontáneamente algunos opinan que inicialmente solo es necesario tranquilizar y explicar al paciente el curso normal de esta enfermedad. Otros abogan por los ejercicios de "reposicionamiento canalicuar" como instrumento para acelerar la recuperación las cuales se describen como de alta efectividad 9,10,19,20,47. Estos consisten en realizar una serie de maniobras en el paciente con el supuesto fin de extraer el cálculo del canal semicircular posterior afectado y guiarlo hacia el acueducto vestibular donde será eliminado. EI cuadro 6 muestra un resumen de las características clínicas de estas dos entidades.

\section{Vértigo periférico crónico persistente}

A fortunadamente la mayoría de los padecimientos vertiginosos son autolimitados. Sin embargo, a veces las crisis pueden ser interminablemente recurrentes o persistentes e incluso pueden incapacitar para trabajar y disminuir la calidad de vida de forma importante. Para los pocos casos en que esto sucede y si es posible ubicar la enfermedad en un solo oído, se puede ofrecer al enfermo alternativas invasivas.

L a descompresión quirúrgica del saco endolinfático ${ }^{17,22,4,48}$ se utiliza para la enfermedad de M eniere y es quizá el procedimiento invasivo más utilizado en el país para lidiar con este padecimiento. También se ha descrito la sección del nervio vestibular ${ }^{49}$ y la saculotomía ${ }^{50}$ a través de la ventana oval. La instilación de aminoglucósidos ${ }^{51,52,53}$ en el oído medio, denominada "laberintectomía química", es utilizado en algunos centros en el extranjero; sin embargo, no se ha documentado su uso en Costa Rica.

Para el vértigo postural paroxístico benigno se describe la sección quirúrgica del nervio del canal semicircular posterior ${ }^{54} 0$ la obliteración de este. En los casos en que la audición se encuentra muy deteriorada 0 ausente en el oído afectado, como en algunos casos de enfermedad de M eniere y en fístulas perilinfáticas se util iza la laberintectomía con destrucción del oído interno ${ }^{17,22,55}$.

\section{Vértigo psicógeno}

A partado siempre difícil y comprometedor. El factor psicológico puede explicar todo el cuadro, o puede ser solo un componente distorsionador asociado a causas orgánicas. El cuadro 7 resume algunos datos que pueden sugerir su participación ${ }^{56,57}$. En los cuadros súbitos e intensos quizá el mecanis-

mo más frecuente sean los fenómenos metabólicos asociados a la hiperventilación ${ }^{13}$. La prueba de Romberg y sus variantes merecen una palabras. Se considera positiva si al colocar al examinado en posición supina y con los pies juntos (o uno delante del otro), se observa que la inestabilidad aumenta apreciablemente al pedírsele que cierre los ojos. Esto sugiere una alteración de la propiocepción (lesión de cordones posteriores de la médula espinal, que se describe por ejemplo en la tabes dorsal sifilítica), aunque algunos autores opinan que en alteraciones cerebelosas 


\section{Cuadro 7. Hallazgos que sugieren componente psicógeno. Síntomas depresivos asociados.}

- Cuadro atípico y abigarrado, difícil de clasificar.

- Paciente refiere síntomas muy desproporcionados con respecto a hallazgos objetivos.

- Historia cambiante y contradictoria.

- Vertigo periférico como más de 3 semanas sin mejoría

- Evento emocional desencadenante.

- El paciente achaca el cuadro a conflictos personales (pareja, hijo-padre)

- Prueba de Romberg que se negativiza al hacerla con distracción

- Base de sustentación pequeña a pesar de desequilibrio evidente.

puede positivarse discretamente. En algunos pacientes al realizarse esta prueba resulta inicialmente positiva, pero al repetirla pidiéndole que haga cálculos matemáticos simultáneamente (como contar para atrás de dos en dos desde cien), se "le olvida que debe caerse", por lo que el resultado se invierte. Desde que los autores repiten de este modo la prueba, no han vuelto a ver pruebas de Romberg positivas, pero se ha convertido en otra valiosa manera de "medir" el factor psicógeno. También es de utilidad observar la manera en que se mantiene de pie la persona que se queja de inestabilidad importante, las personas con afecciones orgánicas tienden a tener los pies separados (base de sustentación amplia), mientras que las de origen psicógeno tiende a tener los pies más juntos.

\section{Asoreguladores y "oxigenadores" cerebrales}

Son ampliamente utilizados en nuestro país a pesar de que su utilidad es controvertida y no existe literatura de consenso que los indique en el vértigo periférico.

\section{Palabras finales: Integración}

En la dilucidación de la causa de una enfermedad vertiginosa la sola duración de la crisis puede orientar de manera importante como se resume en el cuadro 8. El cuadro 9 muestra un algoritmo de cuatro preguntas que puede ayudar a ordenar la evaluación de los pacientes. Pero lo más importante sigue siendo un adecuado interrogatorio.

El diagnóstico, y por ende, la conducta correcta ante un padecimiento vertiginoso depende del conocimiento y la sagacidad del clínico. "El que no sabe lo que busca, no entiende lo que encuentra".
Cuadro 8. Duración del episodio vertiginoso según la entidad que sugiere.

$\begin{array}{ll}\text { Segundos } & \text { Vertigo paroxístico benigno } \\ & \text { Fístula perilinfática } \\ \text { Minutos } & \text { Isquemia Cerebral } \\ \text { Horas } & \text { Enfermedad de Meniere, Migraña } \\ \text { Días } & \text { Neuronitis vestibular } \\ \text { Meses } & \text { Enfermedad progresiva del SNC } \\ & \text { Psicógeno }\end{array}$

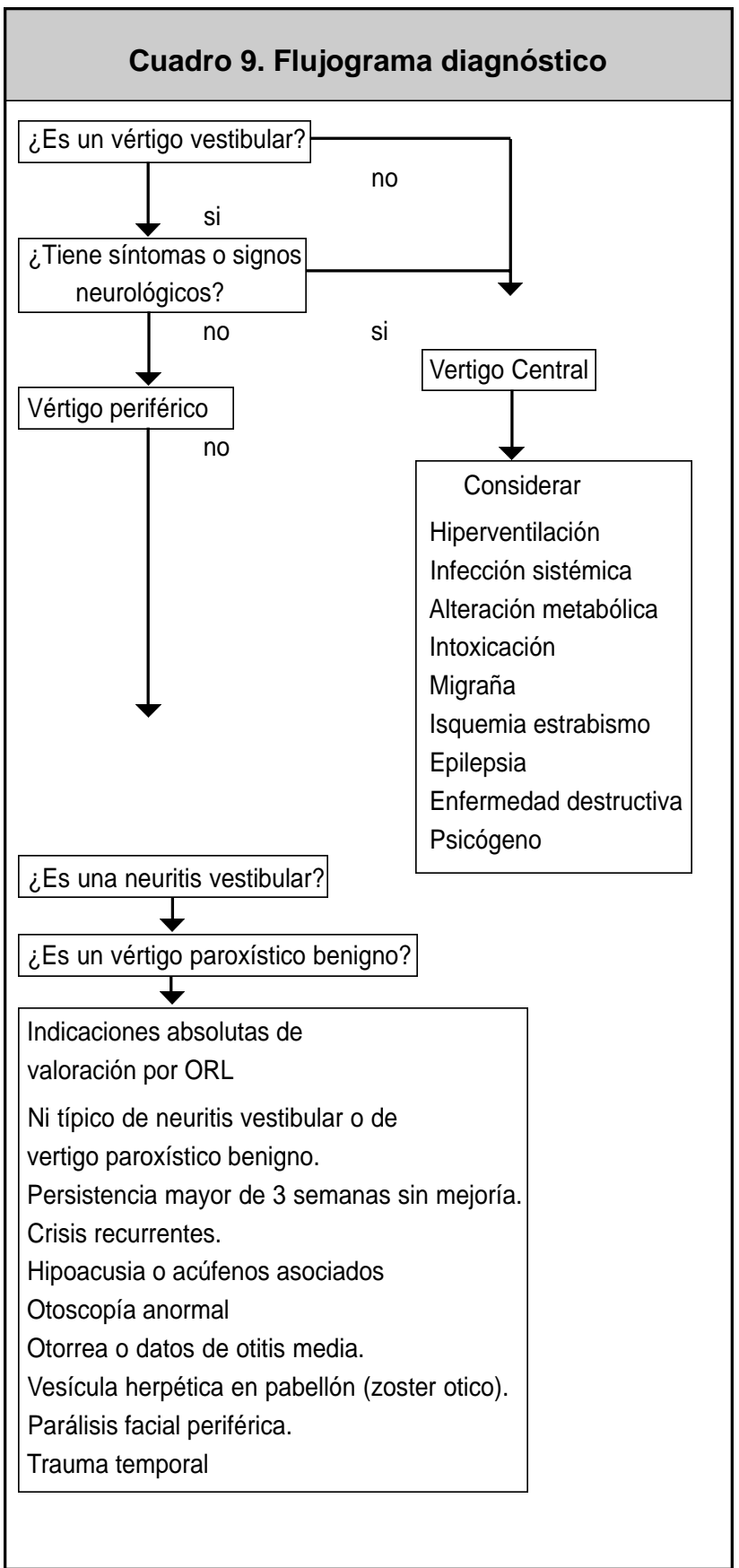


Agradecimiento:

Dr. Edgar Chiossone L ares, actual Presidente de la Sociedad Panamericana de Otorrinolaringología y Cirugía de Cabeza y Cuello y presidente de la Fundación Venezolana de O tología. Dr. J oaquín Berrocal Binde, actual Presidente de la A sociación Costarricense de Otorrinolaringología y Cirugía de Cabeza y Cuello, jefe del Servicio de Otorrinolaringología del Hospital San J uan de Dios. Dr. M artín Nassar Jacobo, jefe del Servicio de Otorrinolaringología del Hospital Nacional de Niños. Dr. Julián Chaverri Polini, jefe de Servicio de Otorrinolaringología del Hospital M éxico. Dr. Mauricio Buitriago Poveda. Hospital Clínica Bíblica. Dr. Juan José Madriz. Fonoaudiologo. Hospital Nacional de $\mathrm{Niños.}$

Q uienes revisaron, aportaron sus opiniones e hicieron correcciones valiosas en este trabajo. Sin embargo, se aclara que las inexactitudes o errores que pudieran encontrarse son en entera responsabilidad de los autores.

\section{Abstract}

$M$ any illnesses show themselves with various symptoms described as "vertigo" or "dizziness". From very mild ailments to potentially mortal diseases can present with this symptoms this generates some fear to face the tasks of reaching a diagnosis. This paper tries to summarize the practical experience of an otolaryngologist, aimed to improved the general physician's ability to solve the diagnostic challenge. Central and peripheral vertigo's causes and characteristic are described, followed by basic treatment recommendations. Finally, a general four steps algorithm is proposed.

\section{Referencias}

1. Las referencias resaltadas con “* " son revisiones que los autores recomiendan para extender la lectura del tema:

2. Shepard, Neil T. Funcional operation of the balance ystem in daily activities. Otolaryngol Clin North A m 2000, J un: 33(3):455-69

3. Cohen, NI. Pacientes con vertigo: actualización sobre transtornos vestibulares. Clin Med Nort A m 1991 : 1333-42

4. Smith, DB. Dizzness: a clinical perpective. Neurol Clin 1990 May, 8(2): 199-207

5. Hard, CW. Clinical evaluation of the dizzy patient. En: Hughes, CB. Clinical Otonlogy: Thierme, 1997: 345-66

6. Brown. JJ. A systematic to the dizzy patient. Neurol Clin 1990 May, 8(2): 209-24.

7. Deweese, H. Diagnóstico diferencial del mareo y vértigo. En: Parella, M. Otorrinolaringología. Ed M édica Panamericana, 1994: 1970-1976.

8. Linstrom, C. A tención al paciente mareado. Clin Otorrinol Nort A m $1992,785-824$

9. Gillipie, M, B oyd. Prognosis in bilateral vestibular hypofuction. Laryngoscope 1999 Jan: 109(1):35-41.

10 Kashlan, Hussan. Diagnosis and initiang treatement for peripherical system disorder: Imbalance and dizzness with normal hearing. Otolaryngol Clin North A m 2000:33(3):563-78
11. Cohen, Helen. Efficacy of treatement for posterior cana bening paroxystical vertigo. Laryngoscope 1999 A pril: 109(4):584-90.

12. M erchant, sunil N. Temporal bone studies of the human peripheral vestibular system: normative vestibular hair cell data. Ann Otol Rinol L aryngol. 2000:109 (5pt2 suppl 181):3-13

13. Baloh, RW. Otología neurological. Clin Neurol Nort A m. 1996: 1:93110.

14. Drachmann, DA. A n approach to the dizzy patient. Neurology 1972: 22(4):322-334 Eviatar, L. Vértigo. Clin Otorrinol Nort A m. 1994:3: 547-60.

15. Velásquez, Luis. Temporal bone studies of the human peripheral vistibular: normative Scarpa's ganglion cell data. Ann Otol R hinol Laryngol. 2000: 109 (5 pt 2 suppl 181): 14-19.

16. Tsuji Kojiro. Temporal bone studies of the human peripheral vestibular: aminoglycoside ototoxity. A nn Otology Rhinol Lariyngol. 2000. 109 (5 pt 2 suppl 181): 20-25.

17. Goycoolea, M arcos V. A spectos generales y justificación de alternativas quirúrgicas para tratar el vértigo periférico incapacitante. Clin Otorrinol Nort A m. 1994: 2:293-310.

18. *Ruckenstein, Michael J. Balance function testing Otolaryngol Clin North A m. 2000:33(3):507-18.

19. Furman, J oseph. Treatement of B ening positional vertigo using heelsover-head rotation. Ann Otol Rhinol Laringol. 1998 Dec: 107(12):1046-53.

20. Epley, John. Reposición de partículas para tratar el vértigo postural paroxístico benigno. Clin Otorrinol Nort A m. 1996:2:329-38.

21. *Walker, Mark F. Bedside vestibular examination. Orolaryngol Clin North A m. 2000:33(3):495-506

22. La Rouse, M ichael. Tratamiento quirúrgico de la enfermedad de Me niere. Clin Otorrinol Nort A m. 1996: 2:317-28.

23. Ruckenstein, MJ. Vertigo and dysequilibrium with associated hearing loss. Otolaryngol Clin N orth A m. 2000: 33(3): 535-62.

24. Brookles, Kh. El sistema vestibular y su patología. En: Lee, KJ. Lo esencial en otorrinolaringología: Appleton and Lange, 1995: 91-124

25. Conlon, Bredan J. Meniere's Disease: the incidence of hydrops in the contralateral asyntomatic ear. Laryngoscope. 1999 Nov:109(11):1800-2.

26. Tsuji, K ojiro. Temporal bone studies of the human peripheral vestibular: Meniere's disease. A nn Otol Rhinology Laryngol. 2000:109 (5pt2 suppl 181): 26-31.

27. Wolfagan, A rnold. Herpes simplex virus antibodies in the perilynph of patients with Meniere disease. Arch Otol Head Neck Surg. 1997:123(1):53-56.

28. Kumar A. Evaluation of the vestibular system. En: Nadol, JB. Surgery of the ear and temporal bone: Raven Prrs, 1993:57-70.

29. Escajadillo, José Ramón. Oído, nariz, garganta y cirugía de la cabeza y cuello. Ed El M anuel Moderno, 1991: 129-142.

30. Fitzgerald, Dennis C. Perylinfatic fistula: a Washington DC experience. Ann Otol Rhinol Laryngol 1997: 106 (10) pt 1:830-837.

31. Lloyd, B. M inor. Sound-and/or pressure-induced vertigo due to bone dehicense of the superior semicircular canal. A rch Otolaryngol Head Neck Surg. 1998:124 (3):249-60. 
32. M eyerhoff, William L. Fístula perilinfática. Clin Otorrinol Nort Am 1994: 4:409-422.

33. *Salomon, David. Distingishing and treating causes of central vertigo. Otolaryngol Clin North A m. 200: 33(3):579-602.

34. Whithey, Susan L. Physical therapy for migraine-related vestibulopathy and vestibular dysfuction with history of migraine. Laryngoscope. 2000:110(9): 1528-34.

35. Oliveira, Carlos A. M eniere's syndrome and migraine: incidence in one family. A nn Otol Rhinol Laryngol. 1997:106 (10 pt1): 823-29.

36. Grond, M astin. Early intravenous thrombolysis with recombinant tissue-type plaminogen activator in vertebro basilar ischemic stroke. A rch N eurol. 1998:55(4):466-469.

37. Wityk, Robert J. Proximal extracraneal vestibular artery disease in the New England Medical Center Posterior Circulation Registry. Arch Neurol. 1998:55(4):470-480.

38. River, Yason. Spontaneus vertebral artery dissection mimicking acute vertigo. A nn Otol Rhinol Laryngol. 1999:108(12):1170-1173.

39. Wesh, Louis. Vertigo: analysis by magnetic resonance imaging and angiography. Ann Otol Rhinol Laryngol. 200:109(3): 239-48.

40. Welsh, Louis. Basilar artery and vertigo. Ann Otol Rhinol Laryngol. 2000: 109(7):615-22.

41. Caplan, L ouis R. Vertebro basilar disease and thrombolytic treatement. A rch Neurol. 1998:55(4):450-53.

42. *Rosenberg, Michael. N euro-otologic history. Otolaryngol Clin N orth Am. 2000:33(3):471-82.

43. *Chaverri, Julián. Función vestibular. N euroeje 1985:3(3):109-14.

44. Goebel, J oel A. M anegement options for acute versus chronic vertigo. Otolaringol Clin North A m. 2000:33(3):483-94.

45. Whitney, Susan. Efficacy of vestibular rehabilitation. Otolaryngol Clin N orth A m. 2000:33(3): 659-72.

46. Shumway-Cook. A rehabilitation strategies for patiens with vestibular deficit.. Neurol Clin. 1990:8(3): 441-457.

47. Tirelli, Giancarlo. Modified particle repositioning procedure. Laryngoscope 2000:110 (3pt 1):462-8.

48. Paparella, Michael M. Reforzamietno del saco endolinfático. Clin Otorrinol North A m. 1994: 2:381-400.

49. Silverstein Herbert. Sección del nervio singular para el tratamiento del vértigo paxoxístico postural . Clin Otorrinol North A m. 1994:2:35164.

50. M c Donald, Thomas J. Procedimiento de saculotomía. Clin Otorrinol North A m. 1994:2:401-8.

51. Blakley, B rian W. Update on intratympanic gentamicin for M eniere's disease. Laryngoscope 2000:110(2pt 1):236-40.

52. Hellstrom, Sten. Laberintectomía farmacológica. Clin Otorrinol North Am. 1994: 2:315-22.

53. Shea, J ohn J. Perfusión de estreptomicina en el laberinto a través de la ventana redonda y administración por vía intavenosa. Clin Otorrinol North A m. 1994: 2:323-30.

54. Gacek, Richard R. Neurectomía del singular para el tratamiento de vértigo paroxístico postural. Clin Otorrinol North A m. 1994: 2:36580.

18 AM C, enero-marzo 2002, vol 44 (1)
55. Graham M alcolm D. Laberintectomía: indicaciones y Técnica quirúrgica. Clin Otorrinol North A m. 1994: 2:331-40.

56. Yasdley, Lucy. Overview of psychologic effects of chronic dizznes and balance disorders Otolaryngologic. Clin N orth A m. 2000: 33(3): 603616.

57. Staab, J effrey. Diagnosis and tratement of psychologic symptoms and psychiatric disorders in patients with dizzness and imbalance. Otolaryngologic Clin North A m. 2000:33(3): 617-36. 